\title{
Visual comparison of words and random letter strings: Effects of number and position of letters different*
}

\author{
LESLIE HENDERSON† \\ University of Guelph, Guelph, Ontario, Canada \\ and \\ SHEILA E. HENDERSON $\dagger \dagger$ \\ University of Waterloo, Waterloo, Ontario, Canada
}

\begin{abstract}
Ss classified tetragrams as either "same" or "different". Stimuli were either words or consonant strings. In the case of different pairs, the number and position of letters different were controlled. Words were compared faster than random strings under all conditions. Consistent effects of the number and position of letters different suggest that word superiority is not due to phonemic recoding. For both words and consonant strings "same" RT to a given pair was faster when it was from a block in which "different" pairs had three rather than one letter different. This suggests that the wholistic identity reporter involves a criterion process sensitive to the magnitude of expected differences. Different RTs were faster in all conditions fo: three-letter different pairs rather than one-letter different pairs, ruling out a fixed order self-terminating search process for "different" decisions.
\end{abstract}

Traditionally the literature on binary character classification has been identified with the fortunes of the random, serial, self-terminating model (Egeth, 1966; Nickerson, 1972). However, an important recent development has been the demonstration that in "same-different" judgments "same" RTs are consistently faster than this model predicts. This finding has suggested to a number of theorists (see Nickerson, 1972) that "same" decisions are based on a wholistic matching process which, up to some capacity limit (Silverman, 1973), is less sensitive to the number of critical features in the display (Bamber, 1969; Beller, 1970). Such dual-process interpretations have received further support from studies reporting manipulations which affect "same" and "different" RTs selectively (Krueger, 1970, 1973; Egeth \& Blecker, 1971).

It is well established that the comparison of letter strings is facilitated when the string forms a word. This familiarity effect is marked for "same" decisions, being reduced (Eichelman, 1970; Henderson, 1974) or absent (Egeth \& Blecker, 1971; Barron \& Pittinger, 1974) for "different" decisions. Debate about this familarity effect has largely centered on two issues: The operative nature of familarity and the locus of its effect in terms of processing stages.

Eichelman (1970) addressed both issues with the assertion that his effect did not depend on the advantageous use of a name code for words. This claim

* This research was supported by NRC of Canada Jrant A8263. Norman Park and Gay Christofides assisted with lata collection. Rod Barron gave technical assistance.

+ Now at the Department of Psychology, The Hatfield Polytechnic, P. O. Box 109, Hatfield, Herts., England.

+ Now at the Department of Child Development and Educational Psychology, Institute of Education, University of London, Lond on, England. was based on the finding that when letter case differed between member of the stimulus pair all RTs were lengthened but the familiarity effect was undiminished. However, the premise that the sole and necessary effect of case change is to compel use of a name code is questionable. Case change might be debilitating at an entirely visual level. Further, in view of the high residual similarity of same pairs it need not compel name matching. However, other grounds for assuming a visual locus for Eichelman's effect were offered by Posner (1969) who cited the dependence of "different" decisions on the number of letters differing.

Hochberg (1968) introduced the assumption that memory factors are negligible in the simultaneous matching task. From this premise he argued that familiarity effects, which he obtained only for delayed matches, played no role in perceptual (encoding) stages. Subsequently Egeth and Blecker (1971) adopted this assumption. However, they succeeded in obtaining familiarity effects in simultaneous matches which they attributed to encoding speed. Attempts to challenge this zero memory load assumption have been based on hypotheses about the basis of familiarity effects, specifically the postulation of a verbal encodability factor (Friden, 1973).

Eichelman's (1970) familiarity manipulation contrasted words with random letter strings. Subsequent studies have centered on the isolation of the critical aspects of wordness. Egeth and Blecker (1971) attempted to adjudicate between semantic factors and orthographic ones, but their results were equivocal. In their Experiment IV they found that meaningfulness was sufficient cause for a familiarity effect using CVC trigrams. However, in their Experiment VI, where 
meaningfulness was factorially combined with pronounceability, only pronounceability yielded a significant main effect. Meaningfulness just appeared to be useful when pronounceability was low.

Egeth and Blecker's (1971) speculation that pronounceability might be effective in terms of the statistical constraints imposed by orthography has been developed by Baron (1974) who argued that orthographic regularity rather than wordness itself was critical. Baron found no overall difference between words and pronounceable nonwords, though both were superior to unpronounceable strings. Since homophony also had no deleterious effect, Baron concluded that spelling regularities facilitated visual encoding rather than the derivation of a phonetic code.

Bayon's (1974) results included a significant interaction of Meaningfulness by Type of Response (yes/no), such that lexical meaning appeared relatively facilitatory for "same" judgments. Stronger evidence of a lexical effect in same decisions is advanced by Baron and Pittinger (in press), who found, in addition to the orthographic effect (superiority of pronounceable nonwords), a lexical effect whereby real words yielded faster same decisions than nonwords of similar orthographic regularity.

Further evidence of lexical effects in visual comparisons was reported by Henderson (1974), who showed that orthographically irregular strings such as FBI were classified faster than meaningless strings. Henderson argued that these lexical effects nevertheless operated at an encoding level.

On the other hand, comparisons at a name code level have been claimed by Klapp (1971) and Friden (1973) who report a correlation of RT with syllabic length of the stimulus name. ${ }^{1}$

The present experiment is a development of Eichelman's (1970) in which the stimuli are either words or letter strings. Three differences are salient. First, the unpronounceability of the nonwords is assured by deriving them from the words via a rule which substitutes for each vowel a given, visually similar consonant (e.g., $F$ for E). Second, in the case of different stimulus pairs, the position of the difference in the letter row was investigated, as well as the number of different letters. Third, the number of different letters factory was blocked so that same RTs could be compared as a function of the magnitude of the difference of the different pairs in that block.

\section{METHOD}

\section{Subjects}

Twelve paid student volunteers served individually in two sessions of about 40 mins.

\section{Stimuli}

The stimuli were generated as follows. Eight high frequency, monosyllabic, four-letter words were chosen such that each of these base words yielded two sets of four more words. The one-different set consisted of four words, each of which differed
Table 1

The Derivation of Stimulus Words from One of the Eight Base Words

\begin{tabular}{llll} 
Base Word & READ & Nonword & RFXD \\
& HEAD & & RUST \\
1-Different & ROAD & 3-Different & BENT \\
& REND & & FLAT \\
& REAL & & BOND \\
\hline
\end{tabular}

from the base word in one of the four possible letter positions. The three-different set consisted of four words, each of which shared only one of the four possible letters, differing in the other three.

A matched set of pseudorandom consonant strings was generated from the words by substituting for each of the five vowels a visually similar consonant, for $A, E, I, O, U$, respectively, X, F, T, Q, N.

An example of the generation of stimuli from one of the base words is given in Table 1.

The stimuli generated in this way were organized into 64 pairs for each of the four conditions yielded by combining wordness with number of letters different (one vs three). These 64 pairs subdivided into equal numbers of same and different pairs. For each condition, the different pairs were produced by permutating the base string with each of its four derived strings defined by the four possible arrangements of letter positions different.

Same pairs were achieved by using the base string and three of the four derived strings. The string not used was balanced across the eight bases so that each type of derived string was used in six same pairings.

The stimulus pairs were displayed horizontally, one string above the other. They were constructed from upper case letraset transferred to white cards. When displayed in the Scientific Prototype tachistoscope the display subtended about $2.0 \mathrm{deg}$ horizontally and $1.2 \mathrm{deg}$ vertically, each letter being $0.4 \mathrm{deg}$ in height. Background luminance was set at $60 \mathrm{~cd} / \mathrm{m}^{2}$.

\section{Procedure}

A trial was initiated by the $S$ pressing a key which replaced a fixation field with the stimulus pair for $1500 \mathrm{msec}$ after which the fixation field reappeared. Onset of the stimulus started the clock which was stopped by a vocal "yes/no" response via a Scientific Prototype audio threshold device. These responses represented same and different decisions, respectively. (They are generally equal in effectiveness at triggering the voice switch.)

The 64 trials in each of the four conditions (word/nonword by $1 / 3$ letters different for different pairs) were run in a block with two blocks in each of two separate sessions. The ordering of blocks was counterbalanced across Ss. Within each block a random order of trials was established. Half the Ss ran in this order, and half in the reverse order. The first session was prefaced by the instructions, which stressed accuracy, and eight practice trials.

In the case of erroneous responses, the stimuls was reinserted later in the same block.

\section{RESULTS}

\section{Overall Analysis of RT}

Latencies for correct responses were used to calculate mean RTs for each $\mathbf{S}$ in each condition. These were subjected to an analysis of variance with response (same, different) wordness (word, nonword), and magnitude of difference (one letter/three letters) as factors.

The main effects of wordness and magnitude of 
Table 2

Mean Same and Different RTs and Percent Error for Words and Nonwords With a One-Letter and Three-Letter Magnitude of Difference

\begin{tabular}{llccccc}
\hline & & \multicolumn{2}{c}{ Words } & & \multicolumn{2}{c}{ Consonant Strings } \\
\cline { 3 - 5 } \cline { 3 - 6 } Same & 1-Diff & 3-Diff & & 1-Diff & 3-Diff \\
\hline \multirow{3}{*}{ Different } & RT & 744 & 656 & 929 & 811 \\
& E\% & 4.7 & 2.6 & 9.4 & 3.4 \\
& RT & 764 & 679 & 998 & 749 \\
& E\% & 4.4 & 2.3 & 18.7 & 3.4 \\
\hline
\end{tabular}

difference were significant $(F=45.65, \mathrm{df}=1,11$, $\mathrm{p}<.001 ; \mathrm{F}=63.39, \mathrm{df}=1,11, \mathrm{p}<.001)$. The effect of response type was not significant, $F=1.32$, df $=1,11$, $\mathrm{p}>10$.

Among the interactions, significant effects were found for Response by Magnitude of Difference, $F=20.23$, $\mathrm{df}=1,11, \mathrm{p}<.001$, and Wordness by Magnitude of Difference, $F=5.89, \mathrm{df}=1,11, \mathrm{p}<.05$. The third order interaction was also significant, $F=7.83$, $\mathrm{df}=1,11$, $\mathrm{p}<.05$.

The means comprising the third order interaction are shown in Table 2 which also displays the error rates. This table shows that words are invariably faster than nonwords and the 3-different conditions faster than the 1 -different, but word superiority is reduced under the 3-different condition. Furthermore, while same and different RTs do not differ overall, same RTs are faster than different RTs with the small difference but slower with the larger Magnitude of Difference. This interaction is displayed in Fig. 3.

\section{Different RTs}

The different RTs were subjected to two further

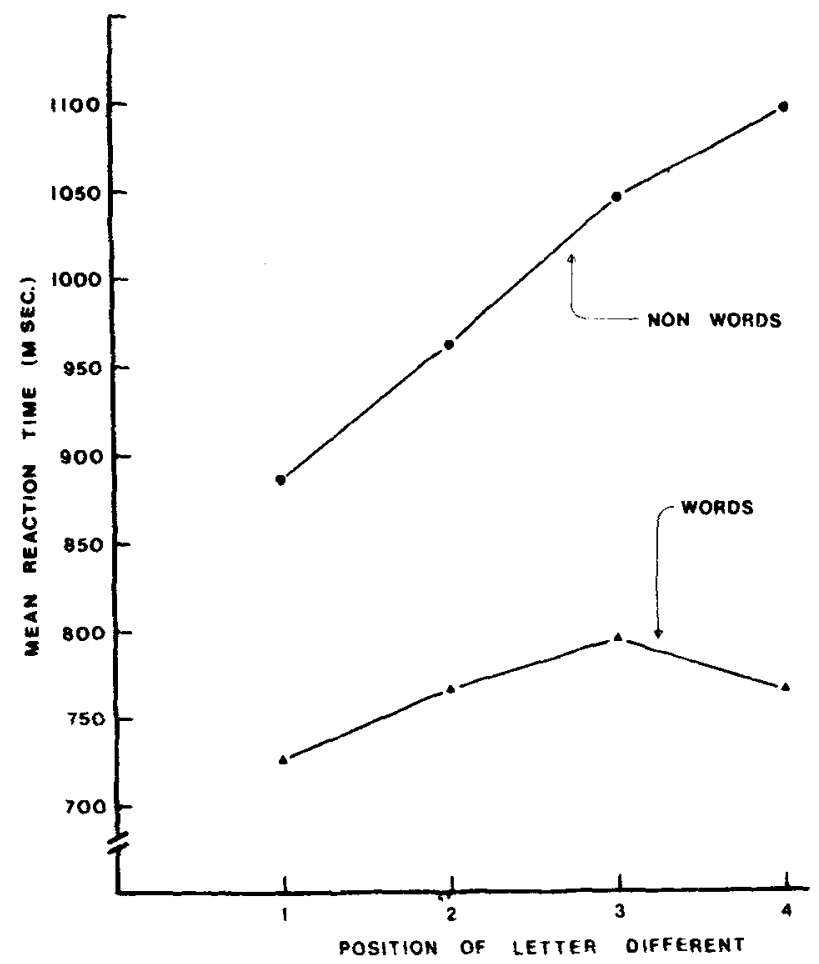

Fig. 1. Mean different RTs to words and nonwords as a function of position of the difference in the one letter different condition.

analyses conducted separately on the 1-different and 3-different conditions with wordness and position as factors. Position is a four-level variable. For convenience, Levels $1-4$ designate the position of the different letter in the 1 -different condition and the position of the shared (same) letter in the 3-different condition.

In the 1-different analysis both main effects and their

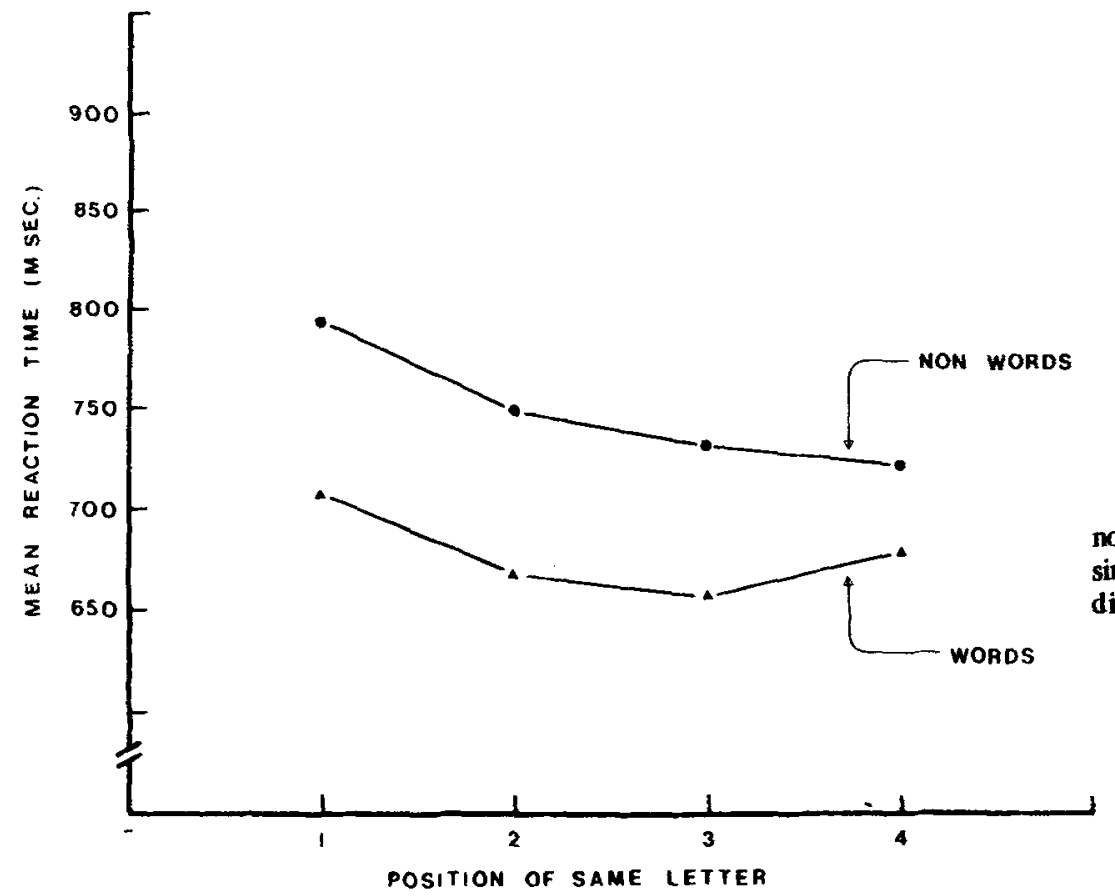

Fiz. 2. Mean different RTs to words and nonwords as a function of position of the single sme letter in the three letters different condition. 
interaction were significant: For wordness $F=20.10$, df $=1,11, p<.001$; for position $F=13.27, \mathrm{df}=3,33$, $p<.001$; for their interaction $F=5.79, \mathrm{df}=3,33$, $\mathrm{p}<.01$. This interaction is shown in Fig. 1 .

In the 3-different analysis both main effects were again significant: For wordness $\mathrm{F}=20.07, \mathrm{df}=1,11$, $p<.001$; for position $F=12.84, \mathrm{df}=3,33, \mathrm{p}<.001$; but the interaction did not approach significance $(\mathrm{F}=1.03)$. These data are shown in Fig. 2 .

\section{Errors}

The overall error rate was $5.0 \%$ for same responses and $7.2 \%$ for different responses. Table 2 shows these errors broken down into conditions. For same decisions the ordering of error rates is perfectly correlated with that of RTs across the four conditions. For different responses this correlation was calculated over the 16 levels resulting when position is combined with magnitude and wordness (rho $=0.82$ ).

These high correlations of RT with error rate seem to preclude the possibility of a tradeoff influencing the pattern of latencies within response types to any substantial extent.

\section{DISCUSSION}

\section{Same Decisions}

Once again same RTs are found to be faster than would be predicted by a serial self-terminating search model. While the overall $12-\mathrm{msec}$ superiority of same RT was not significant, self-terminating search processes require that same decisions be slower than the slowest different decisions. It is evident from Figs. 1 and 2 that different RTs vary considerably as a function of position of the difference and clearly same decisions are considerably faster than the different decisions at positions which are processed slowly.

Dual process theories frequently characterize same decisions as involving "template matching" or "congruence testing." While matches do appear to depend on topographic features of the stimulus (Nickerson \& Pew, 1973), to the extent that matches are sensitive to familiarity variables, it is inappropriate to treat the comparison process as physical congruence testing. The present results provide a further constraint on the template analogy in the finding that same decisions are about $100 \mathrm{msec}$ slowed by a decrease in the magnitude of difference of different pairs from three to one letters. This effect on same RTs of the signal to noise ratio of the classification occurs despite the fact that the same pairs blocked with either of the different sets are directly comparable and include the identical base words. (This effect has not hitherto been detectable because magnitude of difference has not been treated as a blocked variable permitting the corresponding partitioning of same RTs.) Another aspect of this effect is the interaction of Type of Response by Magnitude of

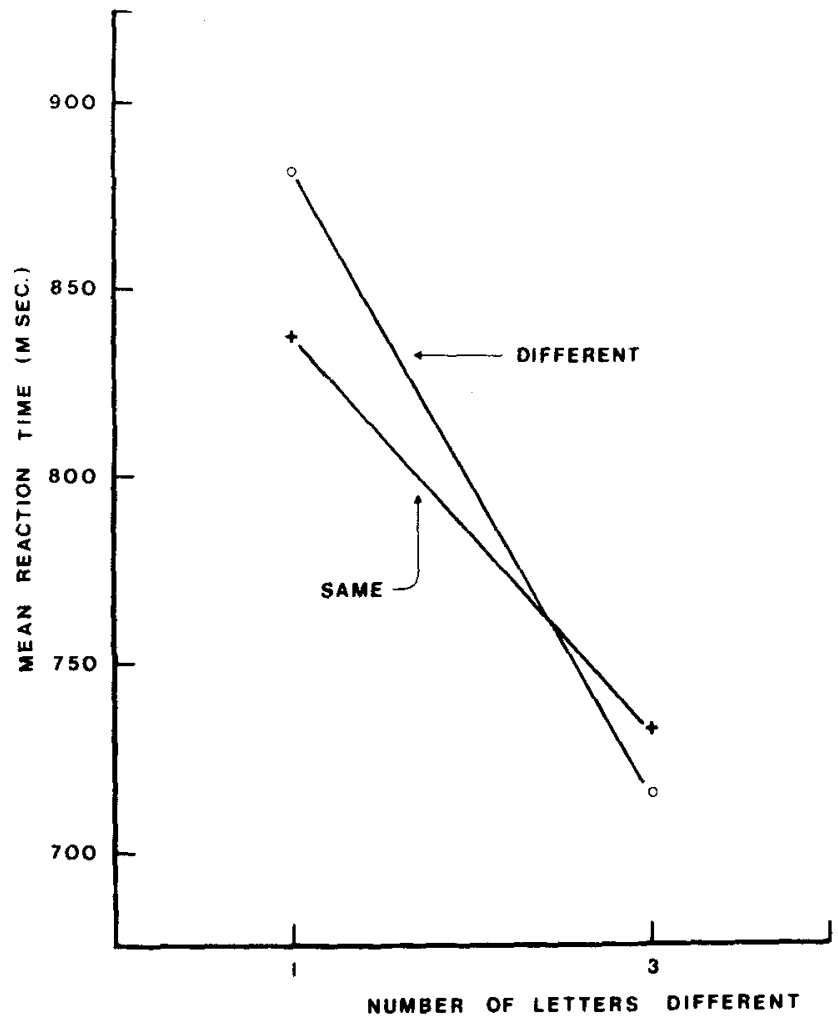

Fig. 3. Mean same and mean different RTs as a function of the magnitude of difference of the different pairs.

Difference which indicates that same decisions benefit less from increases in the magnitude of difference than different decisions, (Fig. 3). From this, it is evident that the relative speeds of same and different decisions cannot be described without taking account of the signal to noise ratio prevailing in the classification.

It would appear, therefore, that the signal to noise ratio is used to determine a criteron for same decisions. This criterion may be regarded as some critical value in an accumulator which represents similarity, or in effect as a coefficient of cross correlation.

\section{Different Decisions}

The idea that letter strings are typically processed serially, left to right is an enduring one in the study of tachistoscopic recognition (e.g., Harcum, 1967). Furthermore, it has been suggested (Mewhort, Merikle, \& Bryden, 1969) that this serial process is faster with familiar letter sequence Perhaps, then, different decisions are to be accounted for in terms of such a fixed order self-terminating search.

A strict version of the left to right model can be rejected for several reasons. First, while the position function for nonwords with one letter different closely fits a straight line (Fig. 1), the function for words does not. ${ }^{2}$ Turning to Fig. 2 , we find the same nonmonotonic function for words differing in three letters. (While the data in the two figures agree on the relative importance 
of letter positions, due to the difference in labeling of the $\mathrm{x}$ axis, one set of functions is inverted with respect to the other.)

A second, more direct, refutation of the fixed order model is found in the comparison of 1-different and 3-different functions, where we find that RT with only Position 1 different (Fig. 1) is considerably slower than when in addition to Position 1 other positions to the right differ (this state of affairs is represented by Position 2, 3, and 4 in Fig. 2). Indeed, even when Position 1 does not differ, a difference of the three rightward letters yields faster RTs than when Position 1 alone differs.

These data seem to require either a variable-order or parallel-search model with weighting of positions. With treatment of wordness and magnitude of difference as blocked variables it may be that these weightings change reflecting the S's strategy for a particular stimulus type. In view, however, of the size of the RT difference between 1-different and 3-different nonword conditions it may be necessary to consider the termination of search not as on location of a single different letter as a discrete event but rather as the accumulation of a critical value in a magnitude of difference "counter." Such a process need not be serial in the strict sense of demanding a decision after a single and final examination of each letter position and the search process may be recursive.

The clear effect of wordness confirms the suggestion of Henderson (1974) that such an effect obtains for different decisions with blocking of the familiarity variable and unpracticed Ss. The contrast with Egeth and Blecker's (1971) and Barron and Pittinger's (in press) lack of an effect for different decisions with randomized wordness suggests a critical involvement of strategies in the familiarity effect.

The consistent position effects for words and the confirmation of an effect of number of letters different offers support to the idea that wordness confers an advantage at the level of visual processing since an exclusively verbal code should be insensitive to such parameters. The possibility cannot be excluded, however, that different decisions about words are the product of a processing race between visual and name codes as Nickerson and Pew (1973) have suggested.

\section{REFERENCES}

Bamber, D. Reaction times and error rates for same-different judgments of multidimensional stimuli. Perception and Psychophysics, 1969, 6, 169-174.

Baron. J. Successive stages in word recognition. In S. Dornic and P. M. A. Rabbitt (Eds.) Attention and Performance $V$. New York: Academic Press, 1974, in press.

Barron, R. W., \& Pittinger, 3 . B. The effect of orthographic structure and lexical meaning on same-different judgments. Quarterly Journal of Experimental Psychology, in press.

Beller, H, K. Parallel and serial stages in matching. Journal of Experimental Psychology, 1970, 84, 213-219.

Eichelman, W. H. Familiarity effects in a simultaneous matching task. Journal of Experim ental Psychology, 1970, 86, 275-282.

Egeth, H, Parallel versus serial processes in multidimensional stimulus discrimination. Perception and Psychophysics, 1966 , $1,245,252$.

Egeth, H. \& Blecker, D. Differential effects of familiarity on judgments of sameness and difference. Perception \& Psychophysics, 1971, 9, 321-326.

Friden, T. P. The effects of familiarity in a perceptual matching task. Perception and Psychophysics, 1973, 14, 487-492.

Harcum, E. R. Parallel function sof serial learning and tachistoscopic pattern recognition. Psychological Review, $1967,74,51-62$.

Henderson, L. A word superiority effect without orthographic assistance. Quarterly Journal of Experimental Psychology. 1974, 26, 301-311.

Henderson, L., Coltheart, M. \& Woodhouse, D. Failure to find a syllabic effect in number naming. Memory and Cognition, $1973,1,304-306$.

Hochberg, J. In the mind's eye. In R. N. Haber (Ed.) Contemporary theory and research in visual perception. New York-Rinehart and Winston, 1968.

Klapp, S. Implicit speech inferred from response latencies in same-different decisions. Journal of Experimental Psychology, $1971,91,262-267$.

Krueger, L. E. Effect of bracketing lines on speed of same-different judgment of two adjacent letters. J ournal of Experimental Psychology, 1970, 84, 324-330.

Krueger, L. E. Effect of irrelevant surrounding $m$ aterial on speed of same-different judgement of two adjacent letters. Joural of Experim ental Psychology, 1973, 98, 252-259.

Mewhort, D. J. K., Merikle, P. M. \& Bryden, M. M. On the transfer from iconic to short-term memory. Journal of Experimental Psychology, 1969, 81, 89-94.

Nickerson, R. S. Binary-classification reaction time $=$ a review of some studies of human information-processing capabilities. Psychonomic Monograph Supplements, 1972, 4(17, whole no. 65).

Nickerson, R. S. \& Pew, R. W. Visual Pattern matching = an investigation of some effects of decision task, auditory codability and spatial correspondence. Journal of Experimental Psychology, 1973, 98, 36-43.

Posner, M. I. Abstration and the process of recognition. In G. H. Bower and J. T. Spence (Eds.) Psychology of learning and motivation. Vol, 3 New York, A cademic Press, 1969.

Silverman, W. P. The perception of identify in simultaneously presented complex visual displays. Memory \& Cognition, $1973,1,459-466$.

\section{NOTES}

1. How ever, Henderson, Coltheart, and Woodhouse (1973) have revealed active sources of confounding in the digit stimuli used by Klapp and Friden and Barron and Pittinger (in press) failed to replicate Klapp's effect with word stimuli.

2. Position functions for words with identical shape were found in an unpublished study with N. Park which replicated the present 1-different condition. 